\title{
Perspectives on ART adherence among Zambian adults living with HIV: Insights raised through the use of HIV-related disability frameworks
}

\section{Abstract}

The roll-out of anti-retroviral treatment (ART) has improved the survival of people living with HIV in Sub-Saharan Africa, and also produced changes in health and functioning that are experienced alongside ART. Disability frameworks, including the WHO International Classification of Functioning Disability and Health (ICF) and the Episodic Disability Framework (EDF), can illuminate helpful questions and solutions for long-term HIV management. The qualitative longitudinal Sepo Study (Sepo, meaning hope) was conducted using a disability lens to understand life on ART. The study followed 35 people (18 women, 17 men) living with HIV and on ART 6 months or longer and recruited through private and public health facilities in Lusaka, Zambia over an 18-month period between 2012-2015. A total of 99 in-depth interviews were conducted. This analysis focused on participants' narratives regarding body function and ART adherence during the research period and what made challenges better or worse, including access to services. Conventional content analysis and NVIVOv10 were applied to analyse the experience of participants.

Participants in this study did not report any major challenges with adherence. Three main themes emerged from the data related to adherence. Firstly, ART was regarded as "giving life,' which underscored adherence. Secondly, all participants described living strategies for adhering to ART despite health and functional limitations. Participants self-managed what they attributed as sideeffects or chronicity through developing low-cost strategies to support adherence. For example, if dizziness was experienced, participants moved administration of medication towards night time. Beyond self-management there was a lack of support. Thirdly, participants described experiences of uncertainty, including the efficacy of new regimens, potential loss of functioning, risk of new health problems, and death.

Long-term ART adherence support for people living with HIV in Sub-Saharan Africa needs to address upcoming functional limitations. Integrating rehabilitation approaches could facilitate this shift in health systems and strengthen both self-management and health service support.

\section{Keywords}

HIV, disability, functioning, Africa, Zambia, adherence, ART

\section{Introduction}

Anti-retroviral treatment (ART) is now widely available in Sub-Saharan Africa (UNAIDS, 2013a), and it has become more critical to assess the challenges and opportunities experienced while living with chronic HIV and adhering long term to ART. The new global development strategies advanced in the 20162030 Sustainable Development Goals, adopted by all United Nations member states in 2015 , include a continued focus on addressing priority health issues 
(Open Working Group of the General Assembly on Sustainable Development Goals, 2015) and ending AIDS by 2030 (UNAIDS, 2014, 2015). Despite recent advances, HIV remains a priority health concern in Sub-Saharan Africa. With widespread access to ART just over a decade old, the need to support people to remain on ART long term with undetectable viral loads is key to ending AIDS in the region (UNAIDS, 2014, 2015). We are only beginning to understand if, and how, people regain quality of life, the longterm health challenges and the living strategies they develop to live with chronic HIV and adhere long term to ART. Adherence to treatment is crucial for the long-term success of the roll out of ART. One of the first systematic review using observational studies of HIV treatment programs reveals that retention to ART in Africa was only $65 \%$ after 36 month and that this may even further drop thereafter (Fox \& Rosen, 2013)]. The high attrition rate was even worse for cohorts enrolled after 2008 when intensive efforts were undertaken to roll-out antiretrovirals in Africa [12]. In response countries now follow focused efforts to improve enrolment, uptake and adherence to ART most predominately advocated in the UNAIDS 90:90:90 targets (UNAIDS, 2014). Currently a number of known adherence challenges are addressed such as transportation, accessibility and stigma. However we do not fully understand if and how other challenges such as disability may impact adherence to ART (Carpenter, Hanass-Hancock, \& Myezwa, 2019).

A number of disabling conditions result from living with chronic HIV, yet this is less frequently discussed in the literature ( $\mathrm{J}$ Hanass-Hancock, Regondi, Van Egeraat, \& Nixon, 2013; S. A. Nixon, Hanass-Hancock, Whiteside, \& Barnett, 2011). These conditions arise as a result of the virus itself (e.g. HIV dementia) (Rackstraw, 2011), the side effects of treatment (e.g. peripheral neuropathy, pain) (Farrant et al., 2014; Meintjes et al., 2012), fragility and aging, (UNAIDS, 2013b) and the long-term effects of coinfection and comorbidities (e.g. tuberculosis) (Petersen, Hancock, Bhana, Govender, \& Mental Health Care, 2013; Sherr, Clucas, Harding, Sibley, \& Catalan, 2011; Smart, 2009). While some of these conditions have decreased in frequency or intensity with improved access to ART, others have increased as people survive longer on ART (Banks, Zuurmon, Ferrana, \& Kuper, 2015; J Hanass-Hancock et al., 2013).

Recent research in South Africa suggests that HIV-related disability is experienced by a significant number of people on ART. In these studies, a large proportion (ranging from 35.5-86\%) of people on ART reported functional limitations which can be understood as mild to moderate disability (Carey, Stein, Zungu-Dirwayi, \& Seedat, 2003; J. Hanass-Hancock, Myezwa, \& Carpenter, 2015; Kietrys et al., 2019; Myezwa, Hanass-Hancock, Pauts, Rulaine, \& Carpenter 2016). These limitations were also associated with depressive symptoms and negative livelihood outcomes (J. Hanass-Hancock, Misselhorn, Carpenter, \& Myezwa, 2017; J. Hanass-Hancock, Myezwa, \& Carpenter, 2015; Myezwa et al., 2016). For the first time, these pilot studies also investigated if functional limitations impact ART adherence, indicating a negative association (Carpenter et al., 2019). In addition, the Episodic Disability Framework (EDF) demonstrated that disability is experienced episodically by 
those living with HIV and associated with uncertainty (O'Brien, Davis, Strike, Young, \& Bayoumi, 2009).

The purpose of this qualitative study was to understand if and how health challenges and functional limitations/disability impact treatment adherence among Zambian women and men on ART over time (S A Nixon et al., 2018).

\section{Methods}

The SEPO II study [43] is a qualitative longitudinal study of thirty-five adults (18 years and older) living with HIV, on ART for 6 months or longer, in two study sites in Lusaka, Zambia (one public and one private health care facility). The sites were chosen for their longstanding histories of ART care, and to facilitate access to participants who met the following inclusion criteria. Participants were purposely recruited for variation in sex, age, time on and whether they received their ART care from a public or private facility (ref). They were informed about the study in writing and verbally. Participation was voluntary and an informed consent form was signed before the first interview.

Three rounds of qualitative interviews, approximately 6 months apart were conducted between December 17, 2012 to April 17, 2015. The interview guide was structured according to the domains in the World Health Organization's International Classification of Function, Disability and Health (ICF) and the Episodic Disability Framework (EDF) developed by O'Brien et al. Both frameworks prompted participants to discuss how living with chronic HIV affects their health and functioning. The ICF also considers environmental and personal contextual factors related to emerging challenges; whereas the O'Brien framework draws attention to experiences of episodic disability and uncertainty.

Interviews were conducted in English, Bemba and/or Nyanja depending on the preference of the participant, audio recorded and transcribed and translated into English. Each interview transcript was coded independently by 2 members of the research team using thematic content analysis, the DEPICT method (Flicker \& Nixon, 2014) and employing NVivo10@ software as a data management tool (ref). The DEPICT model guides qualitative analysis through a collaborative and democratic approach enhancing rigour through inclusion of diverse team members. It uses six sequential steps namely: dynamic reading, engaged codebook development, participatory coding, inclusive reviewing/summarising, collaborative analysing and translating (Flicker \& Nixon, 2014).

The study received ethical approvals from the University of Toronto, Canada; University of Zambia, Zambia; McMaster University, Canada; and the University of KwaZulu-Natal, South Africa. Additional administrative approvals were received from National Health Authority and local health authorities in Zambia.

\section{Results}


Thirty-five men and women participated in a total of 99 in-depth interviews from 2012-2015 (Table 1). Thirty-one participants completed all 3 interviews. All participants had been on ART for several years and been exposed to different ART regimes. Half of the participants changed to Atripla over the period of the investigation. Atripla is a combination of efavirenz, emtricitabine and tenofovir. It has less site effects and needs to be applied only once a day, which has simplified adherence to ART (Bijker et al., 2017).

Insert table 1 Participant Demographics

Three themes emerged from the finding: (1) Adherence to ART is "giving life"; (2) Living strategies for adhering to ART; and (3) Uncertainty and adherence.

\section{Theme 1: Adherence to ART is 'Giving Life'}

Throughout the interviews participants emphasized their commitment to ART. ART was described as "what gives us life", what has "added days to life" and that they would "not be here" without it.

"I know that it [ARVs] is my life because if it was not for the medicine I would not be here so I do not think about it, I just take it." (53 year old woman, 8 years on $A R T$ )

Participants reported improved health, wellbeing and quality of life since they initiated ART. They described feeling "strong, healthy and being able to support the family".

"... without ARVs I would not be where I am today, I feel good because of ARVs, they have helped me to recover since 2004. My body can do any kind of work ... that is what is making me feel nice, my body is back to normal." (44 year old man, 8 years on ART)

Living with chronic HIV and its medication was often perceived as having become part of life and compared to "having become like food" or "shaving cream", which participants described as taking without "second thoughts". Hence, ART was perceived by the study participants as being an integral part of their life ("that this is my life"), personal identity, and participants expressed a feeling of 'normalisation'.

"I think ARVs to me have become part of my life, they have become part of who I am right now" (51 year old man, 12 years on ART)

\section{Theme 2: Living Strategies for Adhering to ART}

Participants experienced health issues, which challenged adherence to ART. Some participants attributed challenges directly to the side effects of HIV. In order to manage these challenges and loss of functioning participants identified the need for 'acceptance', which appeared to motivate adherence. They also described problem-solve strategies to support adherence. 
Participants described memory impairment, weakness, mental health and emotional challenges and reduced mobility and attributed these to side effects of ART. Participants also described co-morbidities such as stroke and tuberculosis and those impacted functioning. Many coping strategies were specific to the participant's goals and situation. For instance, one participant found he could manage his headaches by avoiding walking in the sun. One woman explained that her feet felt "like something has pricked it" and that she tried to make "sure the house is clean and she can walk with her bare feet" to minimize these sensations.

They described how changes in appearance such as a "sunken face", "putting on weight" and "distortion of their body shape" affected their acceptance by others and could influence their daily activities. Despite this, participants were committed to treatment. Participants reinforced that these challenges would "not stop them from taking their medication" as stopping would "create more problems" for them. These participants perceived their health challenges as "manageable". Some participants chose to exercise to counteract their concerns of "putting on weight", "distorting of their body shape" or having lost body strength.

Approximately one-half of the participants changed their ART regime to Atripla over the 18 months of our study and then reported different challenges such as dizziness and sleepiness Participants managed this through taking their medication in the evening after they had eaten and before they went to sleep.

"I would feel dizzy after taking medicine I was taking the medicine at 19:00 hours... So when I want to eat I would feel dizzy and sleep ... That is how I changed at home I started taking it around 20:00 hours after I eat around 19:00". (32 year old woman, 2 years on ART)

Some participants also described issues of memory loss or forgetfulness, which could lead to missing medication. Participants developed strict routine in their lives to ensure that they would adhere to treatment. They also used cell phones and alarm systems to assist as reminders or co-opted family member to provide support.

"I would forget ... especially in the morning, that is when I would forget, before they put me on Atripla I would forget 8:00 hours by the time am coming to remember it is 09:00 hours I have not taken medicine ... what I used is this small phone, you can set the alarm " (33 year old woman, 6 years on ART)

Shifting medication adherence to the evening did not work for everyone. Several men noted there were gender specific expectations related to socializing in the evening hours which challenged adherence. On man noted that taking medication in the evening to avoid drowsiness was difficult because a "man cannot manage to sleep at 20.00, we have a lot of things to do". Several men had made lifestyle adjustments and had stopped socialising through drinking to promote adherence. 
Participants did not discuss their functional limitations, described above, with their health care providers and rather evaluated the seriousness of a problem, if perceived as manageable they would try to deal with it by themselves. For instance, one man who was experiencing fatigue, sweating and forgetfulness which he related to his new ART explained that he did not report these changes to the doctor as there were many people at the clinic and he would only report "a serious problem".

\section{Theme 3: Uncertainty and ART}

While participants were very committed to adhering to their medication they also expressed uncertainties related to the effectiveness of ART over time, including the possibility of medication shortages, worsening side effects or new side effects if they were to change treatment regimens.

One woman described how she felt that she was living "a borrowed life". She worried about the uncertainty of future health challenges. She stated that "... we don't know where we are going to, since we started ARV's, it has been long so we don't know the impact in the future" (49 year old woman, 9 years on ART)

Another woman shared her worries that the medication could "stop working". She explained that "people say you take this medicine for 10 years and then you die".

Worries of uncertainty and health changes also impacted decisions of altering medication. Two participants indicated that they had refused to change their ART regime because of worries about the side effects a new medication might bring. One expressed it in the following way:

The drugs "maybe they will change me ... will make me worse ... Atripler it has caused people a lot of problems ... they complain that they have sleepless nights, there are a lot of dreams even men they have stopped functioning from I mean their bodies, their manhood".

These concern also led some participants to avoid discussions with a health provider, including discussing experiences of side effects, as they expressed a fear of "something else to happen" when there was a change in medication.

Worries and uncertainties were also related to reoccurring thoughts of being still at risk of death, degrading health or loss of functioning. "Going to the clinic and meeting other patients" was seen as "reassuring that the disease does not kill" and that there are others in the "clinic taking medicine".

\section{Discussion}

This paper demonstrates that living long-term with HIV while using ART is accompanied by new health challenges and functional limitations, compensating living strategies and uncertainties, that are addressed mostly by the individual and their families in Zambia. 
Participants recognized the life affirming aspects of ART and adhered to ART in spite of the health and social challenges that they associated with their disease, regimens or additional health conditions. Results highlight how participants tried to self-manage and make adjustments to accommodate these challenges. Participants were largely supported by their family and friends and not professional support through services related to rehabilitation or mental health. Therefore, participants mostly implemented known lifestyle adjustments or utilised technology. Some participants avoided changing their regimes due to uncertainties. None of them reported discussing their issues of functional limitations with their health practitioner or tried to access rehabilitative or other allied health services. Participant rather shared the notion of "needing to accept" as crucial to keep being committed to ART.

Challenges to adhere to ART amongst people living with HIV in Sub-Saharan Africa have been documented in the literature and current efforts focus on improving adherence to ART (UNAIDS, 2014, 2015) and addresses several challenges related to reduce pill burdens, access to ART and overcoming stigma (Bijker et al., 2017). As a result, innovative approaches such as adherence clubs and alternative ways of dispensation have become part of the tool box used by health care providers in recent years.

However, less is known about functional limitations and adherence. One previous cross-sectional study indicated that functional limitations may be negatively associated to ART adherence (Carpenter et al., 2019). Participants in our study, all of whom had been on ART for at least six months, did not reveal serious challenges with adherence as they were committed and had accepted additional challenges as part of living long term with HIV. Through multiple interviews we convey that this sample of participants is very committed to their treatment but that they still experience other health and functional challenges. Strategies to address functional limitations are not widely discussed in the literature, yet rehabilitation approaches can be used to mitigate these limitations (ref). There is an emerging literature describing functional limitations experienced while taking ART, however there is little available concerning coping mechanisms for these functional limitations and how these link to ART adherence (Carpenter et al., 2019; J. Hanass-Hancock, Myezwa, Nixon, \& Gibbs, 2015; J Hanass-Hancock et al., 2013). In addition, literature shows that the experiences of functional limitation among people living with HIV when on ART runs the risk of being overlooked, because these issues are not sees as "clinical important"(Renju et al., 2017). As a result, mitigating services such as rehabilitation or mental health interventions are likely to be forgotten in HIV care and treatment.

However, the WHO Consolidated ART Guidelines (World Health Organisation, 2016) use the term patient-centred approach and mention the need to integrate rehabilitation into HIV-care. Nevertheless, most countries HIV-guidelines and strategic plans are silent on the integration of rehabilitation services. Indeed, Zambia's current antiretroviral treatment guidelines (2016) and National AIDS Strategic Plan 2017-2021 both do not mention rehabilitation or HIV-related functional limitations/disability at all (Ministry of Health of the Republic of 
Zambia, 2016a, 2016b). Research assessing how to integrate rehabilitation that addresses HIV-related disability in Africa is scarce. The existing studies suggest that elements of rehabilitation interventions can be delivered safely and feasible in these settings. Two studies looking at delivering structured physical exercise programmes for people living with HIV in South Africa (Lay, Leach, Barrio, \& Bassett, 2015; Ross, Hellen, van Aswegen, \& Musenge, 2014) revealed positive effects on functionality. These studies also revealed the barriers to physical activity which included low levels of energy, stress levels, family responsibilities, crime and violence, weather conditions, availability or parks and social activities (Roos, Myezwa, \& van Aswegen, 2015) and access to appropriate nutrition (Lay et al., 2015). Another RCT using home-based rehabilitation for people with mobility limitations in South Africa (Cobbing, Hanass-Hancock, \& Myezwa, 2016) revealed that giving information about functioning and how to counteract functioning was enough to initiate change of mild to moderate limitations. Hence, the provision of information to improve selfmanagement of functional limitations might be a potential feasible intervention considering these results as well as our participants reliance of selfmanagement.

The negative impact of uncertainties about medication shortages and lack of social support have been discussed as barriers to ART adherence by other authors and some innovative methods of medication delivery have been developed in recent years (Tshuma et al., 2017; Tsondai et al., 2017). We are hopeful therefore that these worries will be addressed over the next decade. Similarly, this study revealed how social support, reliable health services and sensitive health care staff are crucial for ART adherence. In the Southern African region, remote delivery of ART medication through local facilities and adherence clubs has been explored as feasible solutions to these challenges, with current studies indicating positive results on adherence (Tshuma et al., 2017; Tsondai et al., 2017). However, these models of delivery will not adequately address new health challenges that are experienced over a lifetime on ART. Hence more research focusing on how to integrate HIV and rehabilitation services in Africa is needed.

This research is limited in that it is based on a small number of people living with HIV who are successfully adhering to ART. There is a need to also explore the experiences of those who are not able to adhere to their ART regimes as a result of health challenges. We argue that to more comprehensively support people living with HIV in the long term, the subtle experiences that underlie ART adherence need to be directly addressed by health systems. Rehabilitation is one pillar that could assist people living with HIV to not only survive but also thrive.

\section{Conclusions}

This study demonstrated the application of disability-related frameworks - for understanding experiences of living on ART. Using the ICF and EDF, we previously described functional limitations among people living with HIV (S A Nixon et al., 2018). This paper illuminated how functional limitations may link to other outcomes such as ART adherence. 
The study showed us that people who are committed to ART and live long term with chronic HIV are still experiencing new health related challenges, functional limitations and worries about uncertainties. Although these don't impact ART adherence necessarily, long-term adherence support for people living with HIV in Sub-Saharan Africa needs to address the upcoming functional limitations. Rehabilitation is key to achieving this. Future research should investigate how rehabilitation approaches can be integrated into HIV care and existing health systems and through this strengthen both self-management and potentially ART adherence.

\section{Competing Interest:}

The authors declare that they have no competing interests.

\section{Authors Contribution:}

$\mathrm{JHH}$ wrote the first and final draft of the paper and was part of the team conceptualising the study and developing the research tools. CC, GB, MM, AM and PS have been part of conceptualising the study and/or implementing the study in Zambia. They have also written parts of the paper and reviewed the first and final draft. SN is the PI of the study and has been part of all elements of the study. She has reviewed the first and final draft of this paper.

Acknowledgements: We thank the women and men who courageously shared their personal stories with us so that we can better understand the experiences of living with HIV on ART in Lusaka, Zambia. We also acknowledge our generous collaborators at the two health facilities that participated as study sites.

Funding: This work was supported by the Canadian Institutes of Health Research under Grant 114907.

\section{References}

Banks, L. M., Zuurmon, M., Ferrana, R., \& Kuper, H. (2015). The relationship between HIV and prevalence of disabilities in sub-Saharan Africa: systematic review. Tropical Medicine and International Health, 20(4), 411 $-429$.

Bijker, R., Jiamsakul, A., Kityo, C., Kiertiburanakul, S., Siwale, M., Phanuphak, P., .. . Hamers, R. L. (2017). Adherence to antiretroviral therapy for HIV in subSaharan Africa and Asia: a comparative analysis of two regional cohorts. JIAS, 20(1), 21218. Retrieved from https://www.ncbi.nlm.nih.gov/pmc/articles/PMC5467608/.

Carey, P. D., Stein, D. J., Zungu-Dirwayi, N., \& Seedat, S. (2003). Trauma and posttraumatic stress disorder in an urban Xhosa primary care population: prevalence, comorbidity, and service use patterns. The Journal Of Nervous And Mental Disease, 191(4), 230-236. Retrieved from http://search.ebscohost.com/login.aspx?direct=true \&db=cmedm\&AN=12 695733\&site $=$ ehost-live

http://graphics.tx.ovid.com/ovftpdfs/FPDDNCJCADDGFA00/fs041/ovft/live/gv 012/00005053/00005053-200304000-00003.pdf. 
Carpenter, B., Hanass-Hancock, J., \& Myezwa, H. (2019). Looking at ARTadherence through a disability lens. Disability and Rehabilitation. Disabil Rehabil, in press.

Cobbing, S., Hanass-Hancock, J., \& Myezwa, H. (2016). A home-based rehabilitation intervention for people living with HIV and disability in a resource-poor community, KwaZulu-Natal: A randomized controlled trial. JANAC, 5(1), 77-88

Farrant, L., Gwyther, L., Dinat, N., Mmoledi, K., Hatta, N., \& Harding, R. (2014). Maintaining wellbeing for South Africans receiving ART: The burden of pain and symptoms is greater with longer ART exposure. SAMJ, 104.

Flicker, S., \& Nixon, S. A. (2014). The DEPICT model for participatory qualitative health promotion research analysis. Health promotion international, In press.

Fox, M., \& Rosen, S. (2013). Retention on Antiretroviral Therapy in Low- and Middle-Income Countries: Systematic Review of Papers and Abstracts Since 2008. Retrieved from Boston: https://www.bu.edu/cghd/files/2014/01/HDDP-16-retention-onART.pdf

Hanass-Hancock, J., Misselhorn, A., Carpenter, B., \& Myezwa, H. (2017). Determinants of livelihood in the era of widespread access to ART. AIDS Care, 29(1), 32-39. Retrieved from https://www.ncbi.nlm.nih.gov/pubmed/27350256. doi:10.1080/09540121.2016.1201192

Hanass-Hancock, J., Myezwa, H., \& Carpenter, B. (2015). Disability and Living with HIV: Baseline from a Cohort of People on Long Term ART in South Africa. PLoS One, 10(12), e0143936. Retrieved from https://www.ncbi.nlm.nih.gov/pubmed/26625001. doi:10.1371/journal.pone.0143936

Hanass-Hancock, J., Myezwa, H., Nixon, S. A., \& Gibbs, A. (2015). "When I was no longer able to see and walk, that is when I was affected most": experiences of disability in people living with HIV in South Africa. Disabil Rehabil, 37(22), 2051-2060. Retrieved from https://www.ncbi.nlm.nih.gov/pubmed/25524661. doi:10.3109/09638288.2014.993432

Hanass-Hancock, J., Regondi, I., Van Egeraat, L., \& Nixon, S. (2013). HIV-related disability in HIV hyper-endemic countries: A scoping review. World Journal of AIDS, 3, 257-279.

Kietrys, D., Myezwa, H., Galantino, M. L., Parrott, J. S., Davis, T., Levin, T., ... Hanass-Hancock, J. (2019). Functional Limitations and Disability in Persons Living with HIV in South Africa and United States: Similarities and Differences across the Atlantic Divide. JIAPAC, in press.

Lay, C., Leach, L., Barrio, M. R., \& Bassett, S. H. (2015). Effects of an exercise programme with people living with HIV: research in a disadvantaged setting. African Journal of AIDS Research, 2015. 13(4). African Journal of AIDS Research, 13(4), 313-319. doi:10.2989/16085906.2014.961937

Meintjes, G., Maartens, G., Boulle, A., Conradie, F., Goemaere, E., Hefer, E., . . . Spencer, D. (2012). Guidelines for antiretroviral therapy in adults. South African Journal of HIV Medicine, 13(3), 114-131.

National HIV \& AIDS Strategic Framework 2017-2021, (2016a). 
Zambia Consolidated Guidelines for Treatment \& Prevention of HIV Infections, (2016b).

Myezwa, H., Hanass-Hancock, J., Pauts, N., Rulaine, S., \& Carpenter , B. (2016). Investigating the interaction between disability and depressive symptoms in the era of widespread access to ART. Journal of Acquired Immune Deficiency Syndrome, in press.

Nixon, S. A., Bond, V. A., Solomon, P., Cameron, C., Mwamba, C., Hanass-Hancock, J., ... Yates, T. (2018). Optimism alongside new challenges: using a rehabilitation framework to explore experiences of a qualitative longitudinal cohort of people living with HIV on antiretroviral treatment in Lusaka, Zambia. AIDS Care, 30(3), 312-317. doi:10.1080/09540121.2017.1363365

Nixon, S. A., Hanass-Hancock, J., Whiteside, A., \& Barnett, T. (2011). The increasing chronicity of HIV in sub-Saharan Africa: Re-thinking "HIV as a long-wave event" in the era of widespread access to ART. Global Health, 7(41), 41. Retrieved from https://www.ncbi.nlm.nih.gov/pubmed/22014075. doi:10.1186/17448603-7-41

O'Brien, K., Davis, A. M., Strike, c., Young, N. L., \& Bayoumi, A. M. (2009). Putting episodic disability into context: a qualitative study exploring factors that influence disability experienced by adults living with HIV/AIDS. Journal of the International AIDS Society, 12(30), www.jiasociety.org/content/12/11/30. Retrieved from www.jiasociety.org/content/12/1/30.

Open Working Group of the General Assembly on Sustainable Development Goals. (2015). Full report of the Open Working Group of the General Assembly on Sustainable Development Goals. Issued as document A/68/970, available at http://undocs.org/A/68/970. Retrieved from Geneva:

Petersen, I., Hancock, J. H., Bhana, A., Govender, K., \& Mental Health Care, M. o. P. f. I. (2013). Closing the treatment gap for depression co-morbid with HIV in South Africa: Voices of afflicted women. HEALTH, 05(03), 557-566. doi:10.4236/health.2013.53A074

Rackstraw, S. (2011). HIV-related neurocognitive impairment- A review. Psychology, Health \& Medicine, 16(5), 548-563.

Renju, J., Moshabela, M., McLean, E., Ddaaki, W., Skovdal, M. S., Odongo, F., ... Wringe, A. (2017). 'Side effects' are 'central effects' that challenge retention in HIV treatment programmes in six sub-Saharan African countries: a multicountry qualitative study Sex Transm Infect, 93(3), 1-5. Retrieved from https://sti.bmj.com/content/sextrans/93/Suppl 3/e052971.full.pdf.

Roos, R., Myezwa, H., \& van Aswegen, H. (2015). "Not easy at all but I am trying": barriers and facilitators to physical activity in a South African cohort of people living with HIV participating in a home-based pedometer walking programme. AIDS Care, 27(2), 235-239. Retrieved from https://doi.org/10.1080/09540121.2014.951309. doi:10.1080/09540121.2014.951309

Ross, R., Hellen, M., van Aswegen, H., \& Musenge, E. (2014). Benefits of an education and home-based pedometer walking program on ischemic 
heart disease risk factors in people infected by HIV: a randomised trail. Journal of Acquired Immune Deficiency Syndromes, 67(3), 268-278.

Sherr, L., Clucas, C., Harding, R., Sibley, E., \& Catalan, J. (2011). HIV and Depression - a systematic review of interventions. Psychology, Health \& Medicine, 16(5), 493-527.

Smart, T. (2009). Mental health and HIV: a clinical review. HIV \& AIDS Treatment in Practice, 145, 1-22.

Tshuma, N., Mosikare, O., Yun, J. A., Alaba, O. A., Maheedhariah, M. S., Muloongo, K., \& Nyasulu, P. S. (2017). Acceptability of community-based adherence clubs among health facility staff in South Africa: a qualitative study. Patient Prefer Adherence, 11, 1523-1531.

Tsondai, P. R., Wilkinson, L. S., Grimsrud, A., Mdlale, P. T., Ullauri, A., \& Boulle, A. (2017). High rates of retention and viral suppression in the scale-up of antiretroviral therapy adherence clubs in Cape Town, South Africa. Journal of the International AIDS Society, 20(4), e21649.

UNAIDS. (2013a). Access to antiretroviral therapy in Africa. Status report on progress towards the 2015 targets. Retrieved from Geneva:

UNAIDS. (2013b). HIV and Aging. A special supplement to the UNAIDS report on the global AIDS epidemic 2013. Retrieved from Geneva:

UNAIDS. (2014). 90-90-90. An ambitious treatment target to health end the AIDS epidemic. Retrieved from Geneva, New York:

http://www.unaids.org/sites/default/files/media asset/90-9090 en 0.pdf

UNAIDS. (2015). UNAIDS Strategy 2016-2021: On the Fast-Track to end AIDS. Retrieved from Geneva: http://www.unaids.org/sites/default/files/media asset/20151027 UNAI DS PCB37 1518 EN rev1.pdf

World Health Organisation. (2016). Consolidated guidelines on the use of antiretroviral drugs for treating and preventing HIV infection: recommendations for a public health approach. Geneva: WHO Retrieved from http://apps.who.int/iris/bitstream/10665/208825/1/9789241549684 eng.pdf?ua $=1$

Table 1: Participant Demographics

\begin{tabular}{|c|c|c|c|}
\hline Category & $\begin{array}{l}\text { Public Health } \\
\text { Facility }(n=28)\end{array}$ & $\begin{array}{l}\text { Private Health } \\
\text { Facility }(n=7)\end{array}$ & $\begin{array}{l}\text { Overall } \\
(n=35)\end{array}$ \\
\hline Age (years) & $\begin{array}{c}\text { mean: } 40.3 \\
\text { range: } 21-56 \text { years }\end{array}$ & $\begin{array}{c}\text { mean: } 42.9 \\
\text { range: } 36-54 \text { years }\end{array}$ & $\begin{array}{c}\text { mean: } 40.8 \\
\text { range: } 21-56 \\
\text { years }\end{array}$ \\
\hline Sex & $\begin{array}{c}15 \text { women } \\
13 \text { men }\end{array}$ & $\begin{array}{c}3 \text { women } \\
4 \text { men }\end{array}$ & $\begin{array}{l}18 \text { women } \\
17 \text { men }\end{array}$ \\
\hline $\begin{array}{l}\text { Time on } \\
\text { treatment (years) }\end{array}$ & $\begin{array}{c}1-13 \text { years } \\
\text { mean: } 5.2 \text { years }\end{array}$ & $\begin{array}{c}\text { 3-12 years } \\
\text { mean: } 8.1 \text { years }\end{array}$ & $\begin{array}{c}\text { 1-13 years } \\
\text { mean: } 5.8 \\
\text { years }\end{array}$ \\
\hline Language & $\begin{array}{l}4 \text { English } \\
15 \text { Nyanja }\end{array}$ & 7 English & $\begin{array}{l}11 \text { English } \\
15 \text { Nyanja }\end{array}$ \\
\hline
\end{tabular}


\begin{tabular}{l|l|l|}
\hline & 9 Bemba & B Bemba \\
\hline
\end{tabular} 